\title{
OPEN New insight into the photocatalytic degradation of organic pollutant over $\mathrm{BiVO}_{4} / \mathrm{SiO}_{2} / \mathrm{GO}$ nanocomposite
}

\author{
Dang Trung Tri Trinh ${ }^{1,2}$, Duangdao Channei ${ }^{2,3}$, Auppatham Nakaruk ${ }^{2,4}$ \& \\ Wilawan Khanitchaidecha ${ }^{1,2}$
}

The nanocomposite of $\mathrm{BiVO}_{4}$-based material has been synthesized by one-step solvent method. The morphological, physical, chemical properties of the nanocomposite have been investigated. The results revealed that the surface area of $\mathrm{BiVO}_{4}, \mathrm{BiVO}_{4} / \mathrm{SiO}_{2}$ and $\mathrm{BiVO}_{4} / \mathrm{SiO}_{2} / \mathrm{GO}$ was $11.13,28.47$ and $43.93 \mathrm{~m}^{2} / \mathrm{g}$, respectively. The structural test by XRD proved that the nanocomposites were monoclinic phase of bismuth vanadate. Adsorption and photocatalytic degradation were two main mechanisms

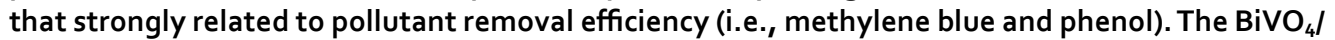
$\mathrm{SiO}_{2} / \mathrm{GO}$ nanocomposite obtained the greatest MB removal efficiency due to its high adsorption ability from high surface area, whereas the photocatalytic degradation was insignificant mechanism. In contrast, the relatively low adsorption ability of $\mathrm{BiVO}_{4} / \mathrm{SiO}_{2} / \mathrm{GO}$ nanocomposite was observed when the pollutant was phenol due to negative charge and high stability of phenoxide ions, then the photocatalytic degradation became the main mechanism for phenol removal. The phenol removal efficiency reached approximately $70 \%$ in $6 \mathrm{~h}$ with $\mathrm{H}_{2} \mathrm{O}_{2}$ assistance. The combination of $\mathrm{SiO}_{2}$ and $\mathrm{GO}$ improved the surface property of $\mathrm{BiVO}_{4}$-based photocatalyst, however the excessive combination ratio generated the excellent adsorbent material rather than the photocatalyst. Hence, the optimal combination ratio is essential to archive the greatest nanocomposite for photocatalytic application.

In recent years, the water pollution has been causing serious problems influencing on the environmental crisis and the human health due to the release of organic wastewater from the rapid development of industries ${ }^{1,2}$. Many technologies have been used to treat and reuse water source such as biological, chemical and physical processes to control pollutants leading to the sustainable development of environment. However, biological processes often require a previous acclimatization or special nutritional conditions, and many pollutants can form toxic or carcinogenic compounds which have a high bio-persistence. In the meantime, physical and chemical processes can generate second byproducts or transfer pollutants into other phases instead of destroying completely pollutants ${ }^{3-5}$. Therefore, advanced oxidation processes (AOPs) have been developed as a promising method for removing organic pollutants from aqueous environment, in which photocatalytic process using semiconductor is receiving much attention of researchers due to its advantages including environmental friendliness, no waste byproducts, complete degradation and mild operating conditions $s^{6,7}$. As the first photocatalyst discovered, titanium dioxide $\left(\mathrm{TiO}_{2}\right)$ has been used widely to eliminate pollutants from water sources for many years ${ }^{8}$. However, the wide bandgap of $\mathrm{TiO}_{2}(3.2 \mathrm{eV})$ is only activated under UV region, which only occupies about 3-5\% of solar light ${ }^{9}$. Therefore, visible light driven photocatalysts have been developed to use thoroughly the energy of solar light.

Among visible light driven photocatalyst, bismuth (Bi)-based photocatalysts have been attracting much attentions ${ }^{10-12}$, in which bismuth vanadate $\left(\mathrm{BiVO}_{4}\right)$ has emerged as an effective photocatalyst due to its excellent properties including inexpensiveness, resistance to corrosion, high physicochemical stability and dispersibility ${ }^{13,14}$. Unfortunately, the photocatalytic activity of $\mathrm{BiVO}_{4}$ is restricted by the weak absorption and the poor migration of charged carriers ${ }^{15,16}$. In order to improve the photocatalytic activity of $\mathrm{BiVO}_{4}$, the combination of $\mathrm{BiVO}_{4}$ with appropriate materials is an effective way to enhance the specific surface area and the crystalline

\footnotetext{
${ }^{1}$ Department of Civil Engineering, Faculty of Engineering, Naresuan University, Phitsanulok 65000, Thailand. ${ }^{2}$ Centre of Excellence for Innovation and Technology for Water Treatment, Naresuan University, Phitsanulok 65000, Thailand. ${ }^{3}$ Department of Chemistry, Faculty of Science, Naresuan University, Phitsanulok 65000, Thailand. 'Department of Industrial Engineering, Faculty of Engineering, Naresuan University, Phitsanulok 65000, Thailand. ${ }^{\bowtie}$ email: wilawank1@gmail.com
} 
structure, leading to the increase of photocatalytic efficiency ${ }^{17}$. Among materials, silicon dioxide $\left(\mathrm{SiO}_{2}\right)$ is known as an inexpensive material, well biocompatibility, large specific surface area, and easy functionalization; that can form $\mathrm{p}-\mathrm{n}$ junction with $\mathrm{BiVO}_{4}$ to enhance the adsorptive ability and the separation of charged carriers ${ }^{7,18-20}$. In addition, graphene oxide (GO) is known as a $2 \mathrm{D}$ carbonaceous material which have large surface area (2630 $\mathrm{m}^{2} / \mathrm{g}$ ), high conductivity and excellent mobility of charged carriers ${ }^{19-23}$. Therefore, GO is used as a favorable anchoring center to prevent the fast recombination of charged carriers, improving further the photocatalytic activity. As a result, it is expected that the combination of $\mathrm{BiVO}_{4}, \mathrm{SiO}_{2}$ and $\mathrm{GO}$ can generate a nanocomposite photocatalyst which have the best efficiency of photocatalytic activity.

Therefore, the objective of this work was to synthesize $\mathrm{BiVO}_{4} / \mathrm{SiO}_{2} / \mathrm{GO}$ nanocomposite by using solvothermal method. The sample was characterized by X-ray diffraction (XRD), scanning electron microscopy (SEM), and Brunauer-Emmett-Teller (BET) to clarify the morphology and crystalline structure. The photocatalytic activity was evaluated by the degradation of methylene blue (MB) and phenol under visible light irradiation. In addition, active species trapping test was also conducted to determine main species during the photocatalytic process of nanocomposite. Based on the obtained results, new insight of photocatalytic degradation of organic pollutant over $\mathrm{BiVO}_{4} / \mathrm{SiO}_{2} / \mathrm{GO}$ nanocomposite was found in the present work.

\section{Methodology}

Chemicals. Bismuth (III) nitrate pentahydrate $\left(\mathrm{Bi}\left(\mathrm{NO}_{3}\right)_{3} \cdot 5 \mathrm{H}_{2} \mathrm{O}\right)$, ammonium metavanadate $\left(\mathrm{NH}_{4} \mathrm{VO}_{3}\right)$, tetraethyl orthosilicate $\left(\mathrm{SiC}_{8} \mathrm{H}_{20} \mathrm{O}_{4}\right)$, graphite flakes, sodium hydroxide $(\mathrm{NaOH})$, sulfuric acid $\left(\mathrm{H}_{2} \mathrm{SO}_{4}\right)$, potassium permanganate $\left(\mathrm{KMnO}_{4}\right)$, hydrogen chloride $(\mathrm{HCl})$, benzoquinone $\left(\mathrm{C}_{6} \mathrm{H}_{4} \mathrm{O}_{2}\right)$, isopropyl alcohol $\left(\mathrm{C}_{3} \mathrm{H}_{8} \mathrm{O}\right)$, ammonium oxalate $\left(\mathrm{C}_{2} \mathrm{H}_{8} \mathrm{~N}_{2} \mathrm{O}_{4}\right)$, hydrogen peroxide $\left(\mathrm{H}_{2} \mathrm{O}_{2}\right)$ were obtained from Sigma-Aldrich and were used as received without any further purification. The $\mathrm{MB}$ and phenol solution were prepared with DI water.

Preparation of graphene oxide. In this work, graphene oxide was synthesized by Hummer's method ${ }^{22}$ with a modification as follows: $1 \mathrm{~g}$ of graphite flakes and $0.5 \mathrm{~g}$ of $\mathrm{NaNO}_{3}$ was mixed in $100 \mathrm{~mL} \mathrm{H}_{2} \mathrm{SO}_{4}$ in an ice bath. Afterward, $6 \mathrm{~g}$ of $\mathrm{KMnO}_{4}$ was added carefully to the mixture to keep the temperature lower than $10^{\circ} \mathrm{C}$ and stirred for $4 \mathrm{~h}$. The ice bath was removed, then the mixture was heated at $35^{\circ} \mathrm{C}$ for $12 \mathrm{~h}$ until it became a pasty brownish mixture. Subsequently, the mixture was cooled down to room temperature and added slowly with $200 \mathrm{~mL}$ of DI water. The obtained solution was reacted further with $5 \mathrm{~mL}$ of $\mathrm{H}_{2} \mathrm{O}_{2}$ to stop reaction. After centrifugation, resultant was washed with HCL (5\%) for 3 times, then with ethanol and DI water for several times to achieve $\mathrm{pH}$ nature. Finally, the obtained sample was dried at $80^{\circ} \mathrm{C}$ for $24 \mathrm{~h}$.

Preparation of nanocomposite. In the meantime, $\mathrm{BiVO}_{4}$-based nanocomposites were synthesized by

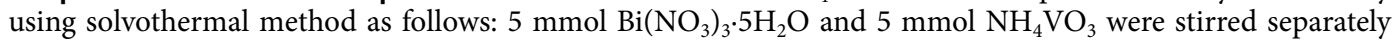
in $50 \mathrm{~mL}$ of ethanol for $30 \mathrm{~min}$. These two solutions were then mixed together with the addition of $1 \mathrm{~mL}$ TEOS and $5 \mathrm{~mL}$ DI water for $1 \mathrm{~h}$ for the preparation of $\mathrm{BiVO}_{4} / \mathrm{SiO}_{2}$ core-shell. The $\mathrm{pH}$ of solution was adjusted to 5 by $2 \mathrm{M}$ of $\mathrm{NaOH}$ solution. After that, the mixed solution was transferred into a Teflon-lined stainless steel and heated at $180^{\circ} \mathrm{C}$ for $10 \mathrm{~h}$. Finally, the resultant was washed with ethanol and DI water for several time, then dried at $80^{\circ} \mathrm{C}$ for $24 \mathrm{~h}$ to achieve the final product. For the preparation of $\mathrm{BiVO}_{4} / \mathrm{SiO}_{2} / \mathrm{GO}$ nanocomposite, the obtained GO was sonicated in $20 \mathrm{~mL}$ of ethanol for $1 \mathrm{~h}$ in the first step. Secondly, $5 \mathrm{mmol} \mathrm{Bi}\left(\mathrm{NO}_{3}\right)_{3} \cdot 5 \mathrm{H}_{2} \mathrm{O}$ and $5 \mathrm{mmol} \mathrm{NH}_{4} \mathrm{VO}_{3}$ were mixed in $100 \mathrm{~mL}$ of ethanol for $30 \mathrm{~min}$, then followed by adding $1 \mathrm{~mL}$ of TEOS and $5 \mathrm{~mL}$ of DI water. In the third step, a calculated amount of GO solution was poured slowly into the above mixture. The fourth step is the $\mathrm{pH}$ adjustment of solution to 5 by $\mathrm{NaOH}$ of $2 \mathrm{M}$. Subsequently, the mixed solution was also heated at $180^{\circ} \mathrm{C}$ for $10 \mathrm{~h}$ in the Teflon-lined stainless steel. After cooling, the $\mathrm{BiVO}_{4} / \mathrm{SiO}_{2} / \mathrm{GO}$ nanocomposites were obtained by washing with ethanol and Di water, which followed by drying at $80^{\circ} \mathrm{C}$ for $24 \mathrm{~h}$. In comparison, pure $\mathrm{BiVO}_{4}$ was also synthesized in the same conditions without the addition of $\mathrm{SiO}_{2}$ and $\mathrm{GO}$.

Characterizations. Crystal phase and structure of the as-synthesized samples were characterized by X-ray diffraction (XRD, Philips X’Pert MPD) using Cu Ka $(\lambda=1.54056 \AA)$ radiation. The morphology was observed by transmission electron microscopy (TEM, JSM-2010, JEOL) and scanning electron microscopy (SEM, JEOL JSM-6335F). Brunauer-Emmett-Teller (BET) measurements (Adtosorb $1 \mathrm{MP}$, Quantachrome) were performed to determine the specific surface area of samples.

Photocatalytic experiments. Typically, the photocatalytic experiments were performed at room temperature as follows: $0.05 \mathrm{~g}$ of photocatalyst was added into $50 \mathrm{~mL}$ of $\mathrm{MB}$ solution $(3 \mathrm{ppm})$. The solution was stirred in dark condition for $30 \mathrm{~min}$ to achieve the adsorption-desorption equilibrium. After that, the solution was irradiated under visible light for $30 \mathrm{~min}$ by fluorescent lamp and the sample was collected every $10 \mathrm{~min}$. The collected sample was centrifuged at $10,000 \mathrm{rpm}$ for $15 \mathrm{~min}$ to remove the photocatalyst from dye solution. Finally, the concentration of dye solution was measured by UV-vis spectrophotometer (UV-6100, Mapada) at the wavelength of $664 \mathrm{~nm}$ to determine the removal efficiency. Additionally, isopropyl alcohol, benzoquinone and ammonium oxalate was used as scavenger for the hydroxyl radical, super oxide, and hole respectively to determine main species during the photocatalytic process of MB.

Besides, the photocatalytic degradation of phenol was also conducted in this work. In which, $50 \mathrm{~mL}$ of $20 \mathrm{ppm}$ phenol solution and a small amount of $\mathrm{H}_{2} \mathrm{O}_{2}(35 \%)$ was stirred with $1 \mathrm{~g} / \mathrm{L}$ of photocatalyst and for 30 min under dark condition. Afterwards, the mixed solution was irradiated under visible light for $360 \mathrm{~min}$. The sample was collected at every $120 \mathrm{~min}$ followed by centrifugation, and then measured at $270 \mathrm{~nm}$ spectrophotometer (UV6100, Mapada) to determine the removal efficiency. 

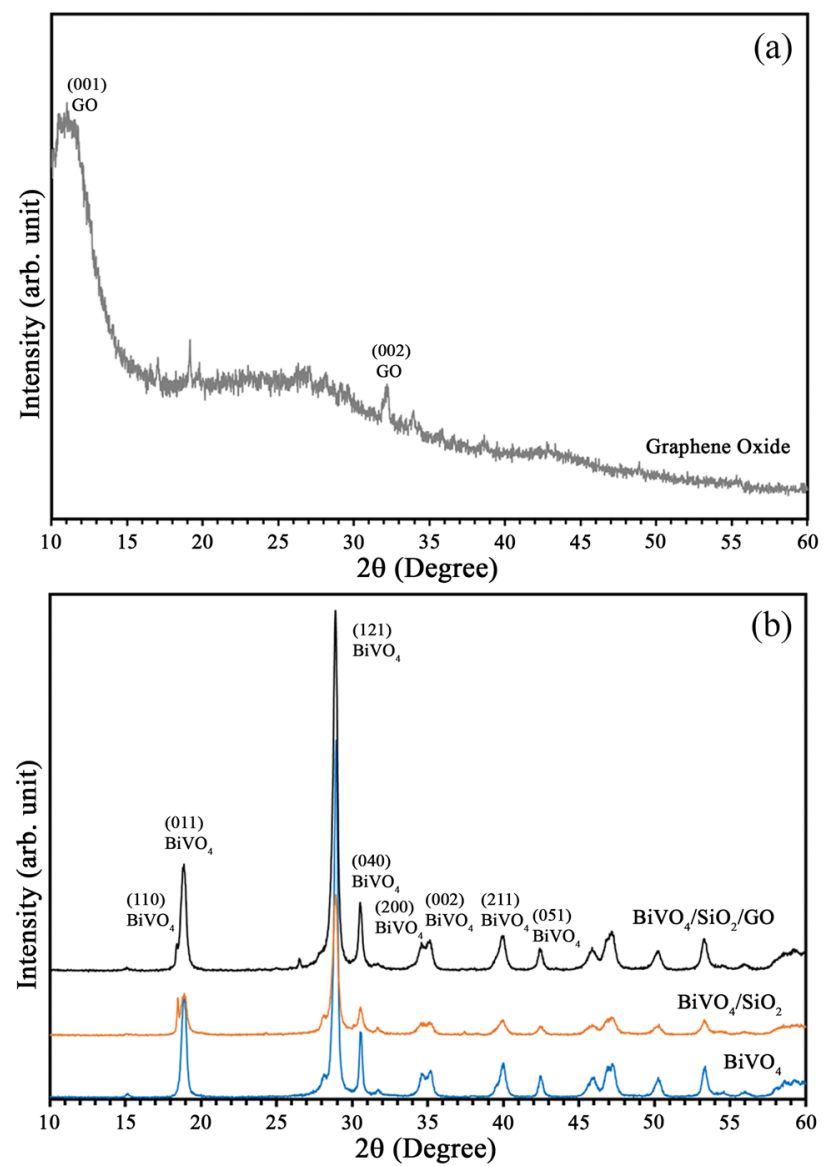

Figure 1. XRD patterns of (a) $\mathrm{GO}$ nanosheets and (b) $\mathrm{BiVO}_{4}, \mathrm{BiVO}_{4} / \mathrm{SiO}_{2}$ and $\mathrm{BiVO}_{4} / \mathrm{SiO}_{2} / \mathrm{GO}$.

\section{Results and discussions}

Characterizations. Figure 1 shows the XRD patterns of GO nanosheets, $\mathrm{BiVO}_{4}$ nanoparticles, $\mathrm{BiVO}_{4} / \mathrm{SiO}_{2}$ core-shell and $\mathrm{BiVO}_{4} / \mathrm{SiO}_{2} / \mathrm{GO}$ nanocomposite. In which, the XRD peak of graphite was mainly observed at around $36^{\circ}$ of $2 \theta$, however this peak was moved to $11^{\circ}$ of $2 \theta$ after graphite was oxidized to graphene oxide. In the meantime, Fig. $1 \mathrm{~b}$ shows that the as-prepared $\mathrm{BiVO}_{4}$ exhibited monoclinic phase corresponding to JCPDS No. 14-0688 which showed the highest photocatalytic activity ${ }^{17}$. Similarly, the diffraction peaks of $\mathrm{BiVO}_{4} / \mathrm{SiO}_{2}$ coreshell and $\mathrm{BiVO}_{4} / \mathrm{SiO}_{2} / \mathrm{GO}$ nanocomposite matched well with the monoclinic peaks of pure $\mathrm{BiVO}_{4}$ and no observation of other impurity peaks, this was due to the much lower content of $\mathrm{SiO}_{2}$ and $\mathrm{GO}$ in composite systems.

The size and morphology of as-prepared samples were investigated via the SEM and TEM analysis, as shown in Fig. 2. It can be seen that the GO nanosheets were formed from thin sheets with wrinkled surface. In the meantime, the $\mathrm{BiVO}_{4}$ and $\mathrm{BiVO}_{4} / \mathrm{SiO}_{2}$ were the aggregation of amorphous nanoparticles with the size of several micrometers. Therefore, they were adhered uniformly on the GO sheets to form $\mathrm{BiVO}_{4} / \mathrm{SiO}_{2} / \mathrm{GO}$ nanocomposite by the reduction of GO to graphene from hydrothermal reaction and the facilitation from the functional groups of GO nanosheets.

Photocatalytic activity. The photocatalytic activity of samples was evaluated by the degradation of organic pollutant including MB and phenol under visible light irradiation as shown in Figs. 3, 6. There were two mechanisms involving the pollutant removal efficiency; adsorption and photocatalytic degradation. From Fig. 3, all samples exhibited a high final efficiency for $\mathrm{MB}$ removal. In which, the $\mathrm{BiVO}_{4}$ nanoparticle adsorbed $35 \%$ of $\mathrm{MB}$ in the dark condition, and further degraded $\mathrm{MB}$ to $70 \%$ after $30 \mathrm{~min}$ of visible light irradiation. By coupling with $\mathrm{SiO}_{2}$, the adsorption of photocatalyst was increased to about $60 \%$, leading to the final $\mathrm{MB}$ removal efficiency of $84 \%$. In the meantime, the $\mathrm{BiVO}_{4} / \mathrm{SiO}_{2} / \mathrm{GO}$ nanocomposite showed the highest final $\mathrm{MB}$ removal efficiency of $94 \%$ with the high adsorption ability of $82 \%$. The reason for excellent $\mathrm{MB}$ removal performance of $\mathrm{BiVO}_{4} / \mathrm{SiO}_{2} /$ GO nanocomposite was that the specific surface area and the pore size were increased significantly by coupling with $\mathrm{SiO}_{2}$ and GO, as determined by BET characterization (Fig. 4 and Table 1).

Figure 4 shows that all samples exhibited $\mathrm{N}_{2}$ adsorption-desorption isotherms type IV and reserved $\mathrm{H} 3$ hysteresis loop ${ }^{24,25}$. This implied that the structures of all as-prepared samples were mesopores (width $=2-50 \mathrm{~nm}$ ), which belonged to the average pore size diameter as reported in Table 1 . The BET surface area and pore volume of $\mathrm{BiVO}_{4} / \mathrm{SiO}_{2} / \mathrm{GO}$ composite were $43.93 \mathrm{~m}^{2} / \mathrm{g}$ and $0.15 \mathrm{~cm}^{3} / \mathrm{g}$; while those of single phase $\mathrm{BiVO}_{4}$ were 11.13 


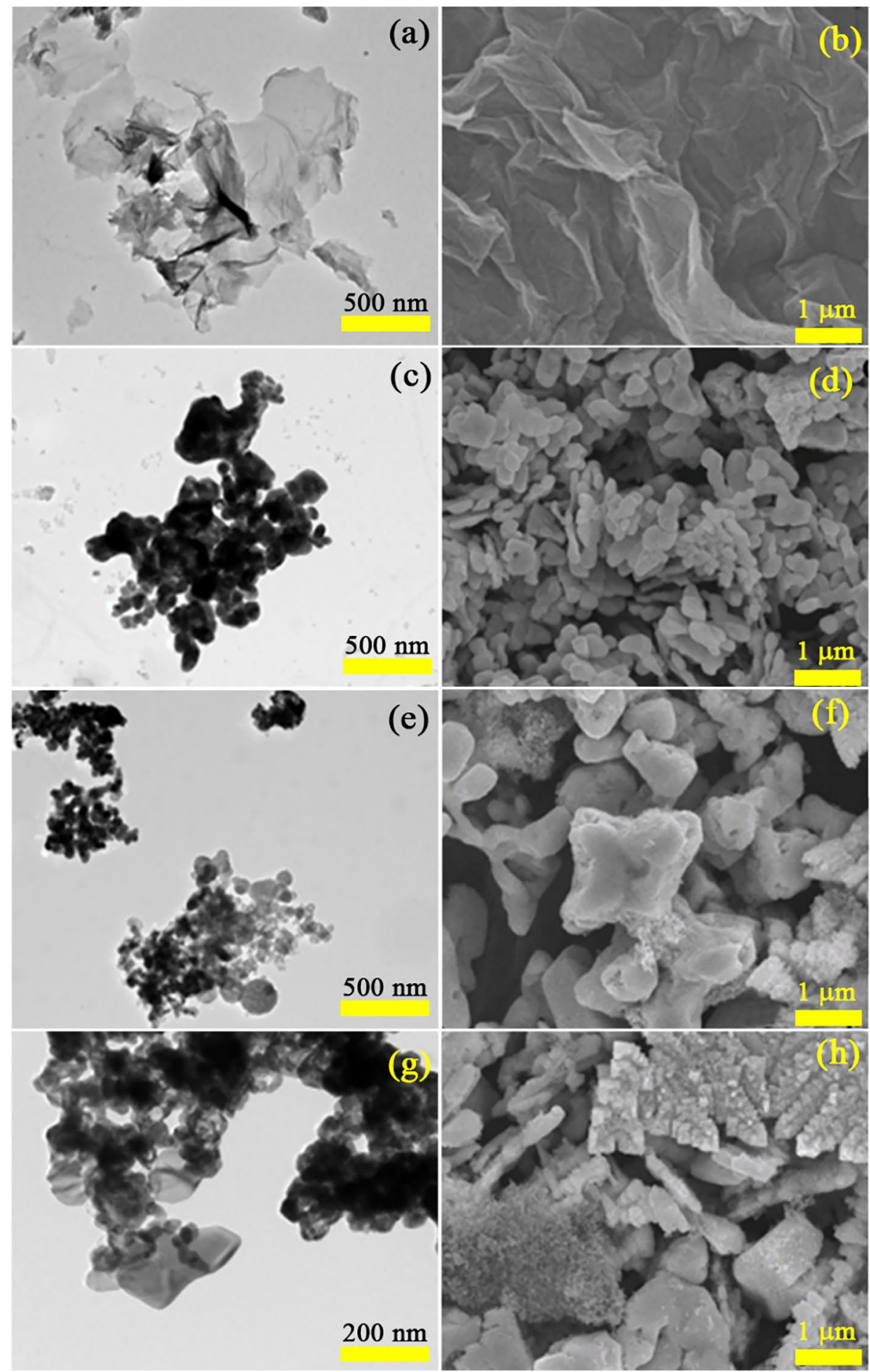

Figure 2. TEM and $\mathrm{SEM}$ images of $\mathrm{GO}(\mathbf{a}, \mathbf{b}), \mathrm{BiVO}_{4}(\mathbf{c}, \mathbf{d}), \mathrm{BiVO}_{4} / \mathrm{SiO}_{2}(\mathbf{e}, \mathbf{f})$ and $\mathrm{BiVO}_{4} / \mathrm{SiO}_{2} / \mathrm{GO}(\mathbf{g}, \mathbf{h})$.

$\mathrm{m}^{2} / \mathrm{g}$ and $0.03 \mathrm{~cm}^{3} / \mathrm{g}$, respectively. The quantity $\mathrm{N}_{2}$ adsorbed as well as other surface properties were found to increase as the $\mathrm{SiO}_{2}$ and $\mathrm{GO}$ were gradually added to $\mathrm{BiVO}_{4}$. The improvement of various surface properties of $\mathrm{BiVO}_{4} / \mathrm{SiO}_{2} / \mathrm{GO}$ were expected to benefit the pollutant to get adsorbed on the photocatalyst surface, which subsequently improved the photocatalytic process under light irradiation.

However, the adsorption ability was a key mechanism of photocatalyst as above discussion. The adsorption kinetic and isotherm of $\mathrm{BiVO}_{4} / \mathrm{SiO}_{2} / \mathrm{GO}$ nanocomposite was analyzed further, as in the supplement (Figures S1-S5, Tables S1, S2). The adsorption kinetic followed pseudo-second-order with a constant rate of $1.86 \mathrm{~g} /$ mg-min. The adsorption isotherm was defined as Freundlich isotherm with a Freundlich constant of $1.38 \mathrm{mg} / \mathrm{g}$.

Although, the nanocomposite exhibited the highest final MB removal efficiency, it was found that the adsorption was extremely high instead of the photocatalytic degradation (Table S3). This meant that the pollutant was 


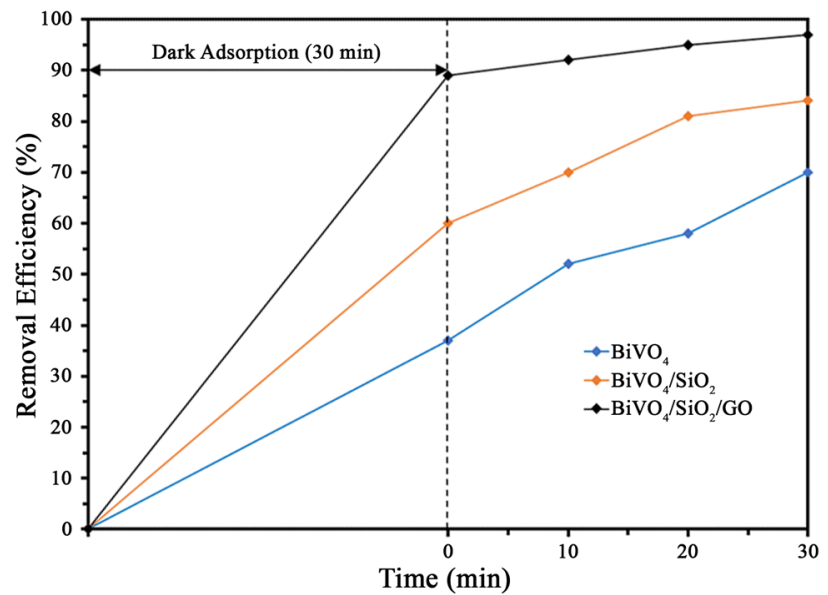

Figure 3. Photodegradation of $\mathrm{MB}$ over $\mathrm{BiVO}_{4}, \mathrm{BiVO}_{4} / \mathrm{SiO}_{2}, \mathrm{BiVO}_{4} / \mathrm{SiO}_{2} / \mathrm{GO}$.

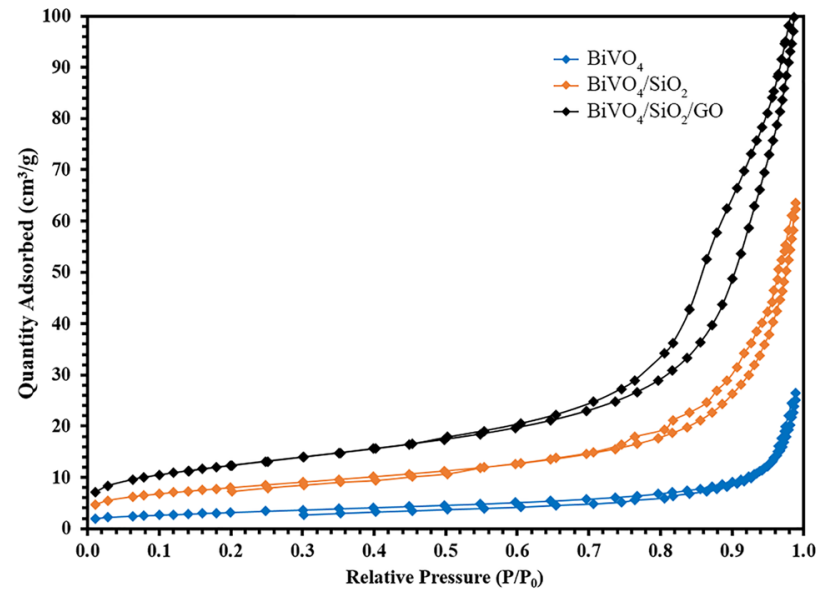

Figure 4. $\mathrm{N}_{2}$ Adsorption-desorption isotherm of as-prepared photocatalysts.

\begin{tabular}{|l|l|l|l|}
\hline Sample & Pore size $(\mathbf{n m})$ & Specific surface area $\left(\mathbf{m}^{2} / \mathbf{g}\right)$ & Pore volume $\left(\mathrm{cm}^{3} / \mathbf{g}\right)$ \\
\hline $\mathrm{BiVO}_{4} / \mathrm{SiO}_{2} / \mathrm{GO}$ & 13.33 & 43.93 & 0.15 \\
\hline $\mathrm{BiVO}_{4} / \mathrm{SiO}_{2}$ & 12.29 & 28.47 & 0.09 \\
\hline $\mathrm{BiVO}_{4}$ & 12.11 & 11.13 & 0.03 \\
\hline
\end{tabular}

Table 1. Surface properties of as-prepared photocatalysts.

not degraded completely to $\mathrm{CO}_{2}$ and water by photocatalytic reactions, they were only trapped on the surface of $\mathrm{SiO}_{2}$ and GO. It demonstrated that the combination of the best ingredients (e.g., $\mathrm{SiO}_{2}$ and GO) could not make an excellent photocatalyst, instead it generated the excellent adsorbent in the present work. This is summarized in Fig. 5. According to the present work, the key mechanism on $\mathrm{MB}$ removal of $\mathrm{BiVO}_{4} / \mathrm{SiO}_{2}$ and $\mathrm{BiVO}_{4} / \mathrm{SiO}{ }_{2} / \mathrm{GO}$ was adsorption, whereas that of $\mathrm{BiVO}_{4}$ was photocatalysis, as calculated in the supplement (Table S3).

In addition, phenol was chosen as a typical toxic pollutant to evaluate the photocatalytic activity of as-prepared samples as shown in Fig. 6. According to literature, phenol exists as phenoxide ions in aqueous environment, which has negative charge and high stability. Therefore, no adsorption of phenol was observed over all samples after $30 \mathrm{~min}$ of dark condition, and no photocatalytic degradation of phenol occurred under visible light irradiation of $6 \mathrm{~h}$. In order to improve the photocatalytic activity for decomposing the highly stable structure of phenol, a small amount of $\mathrm{H}_{2} \mathrm{O}_{2}$ was added into the phenol solution as an assistance. This was because $\mathrm{H}_{2} \mathrm{O}_{2}$ could play an electron acceptor which decreased greatly the combination rate of electron-hole pairs, leading to the increase in hydroxyl radicals (listed in Eqs. 1-3) and then improving the photocatalytic activity. $\mathrm{The} \mathrm{BiVO}_{4}$ 

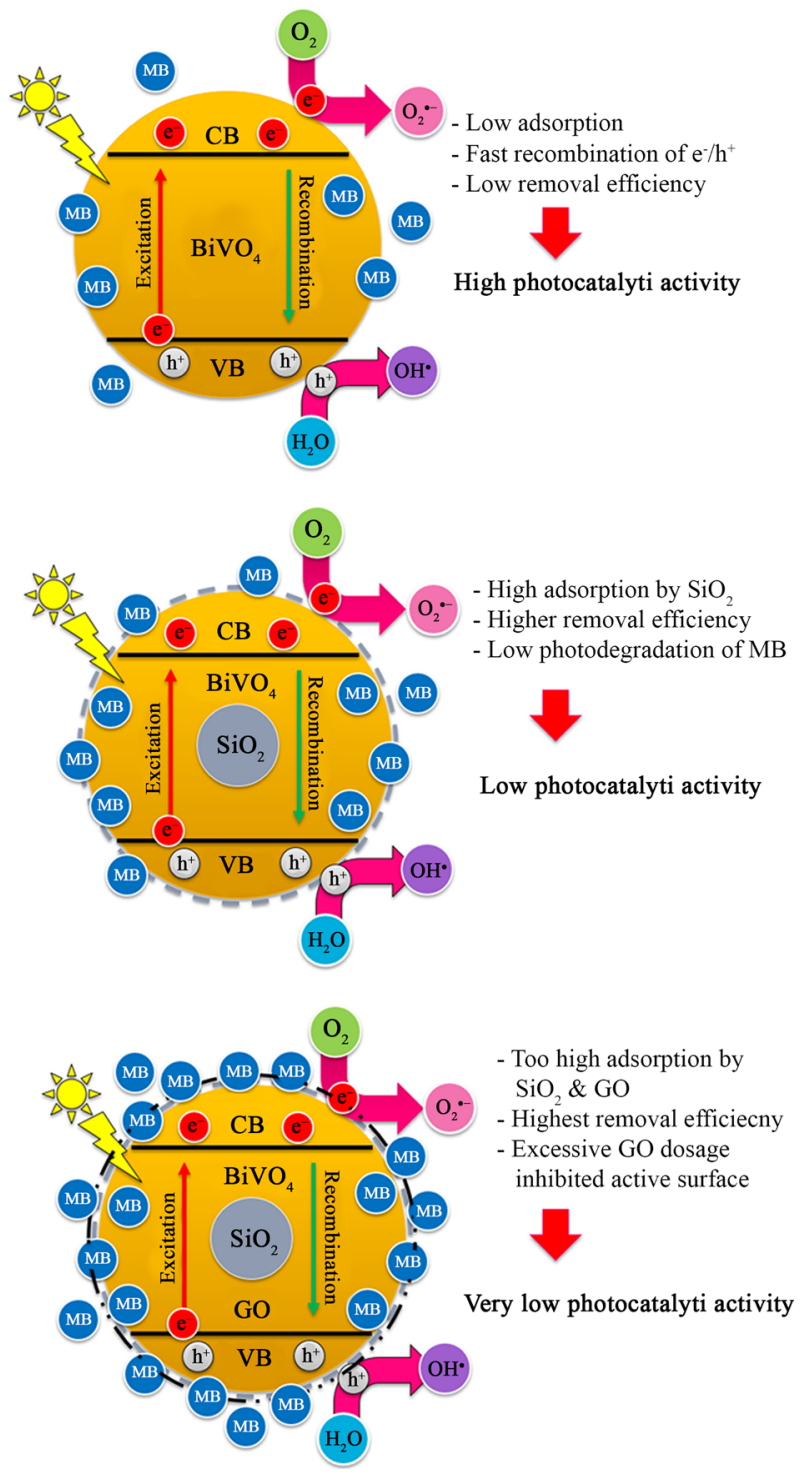

Figure 5. Summary of photodegradation of $\mathrm{MB}$ over $\mathrm{BiVO}_{4}, \mathrm{BiVO} / \mathrm{SiO}_{2}$ and $\mathrm{BiVO}_{4} / \mathrm{SiO}_{2} / \mathrm{GO}$.

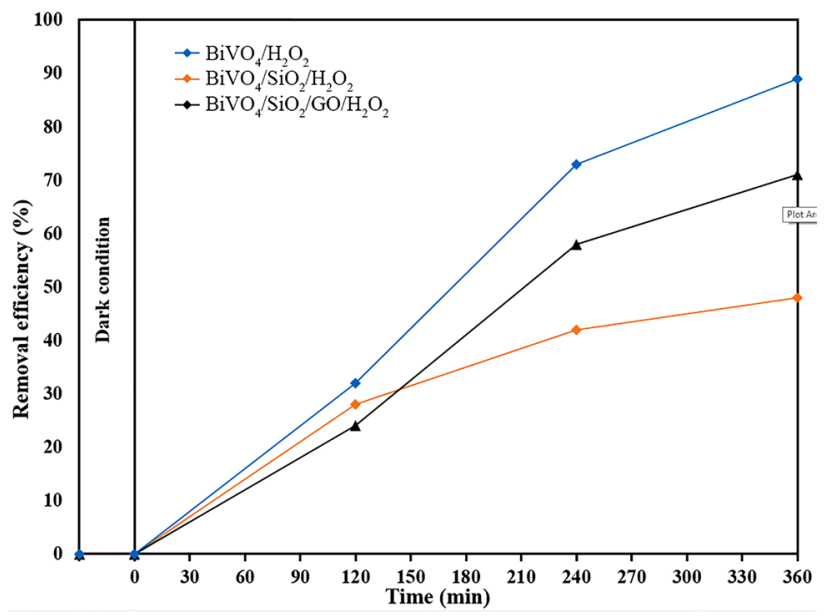

Figure 6. Photodegradation of phenol over $\mathrm{BiVO}_{4}, \mathrm{BiVO}_{4} / \mathrm{SiO}_{2}$ and $\mathrm{BiVO}_{4} / \mathrm{SiO}_{2} / \mathrm{GO}$ with the presence of $\mathrm{H}_{2} \mathrm{O}_{2}$. 


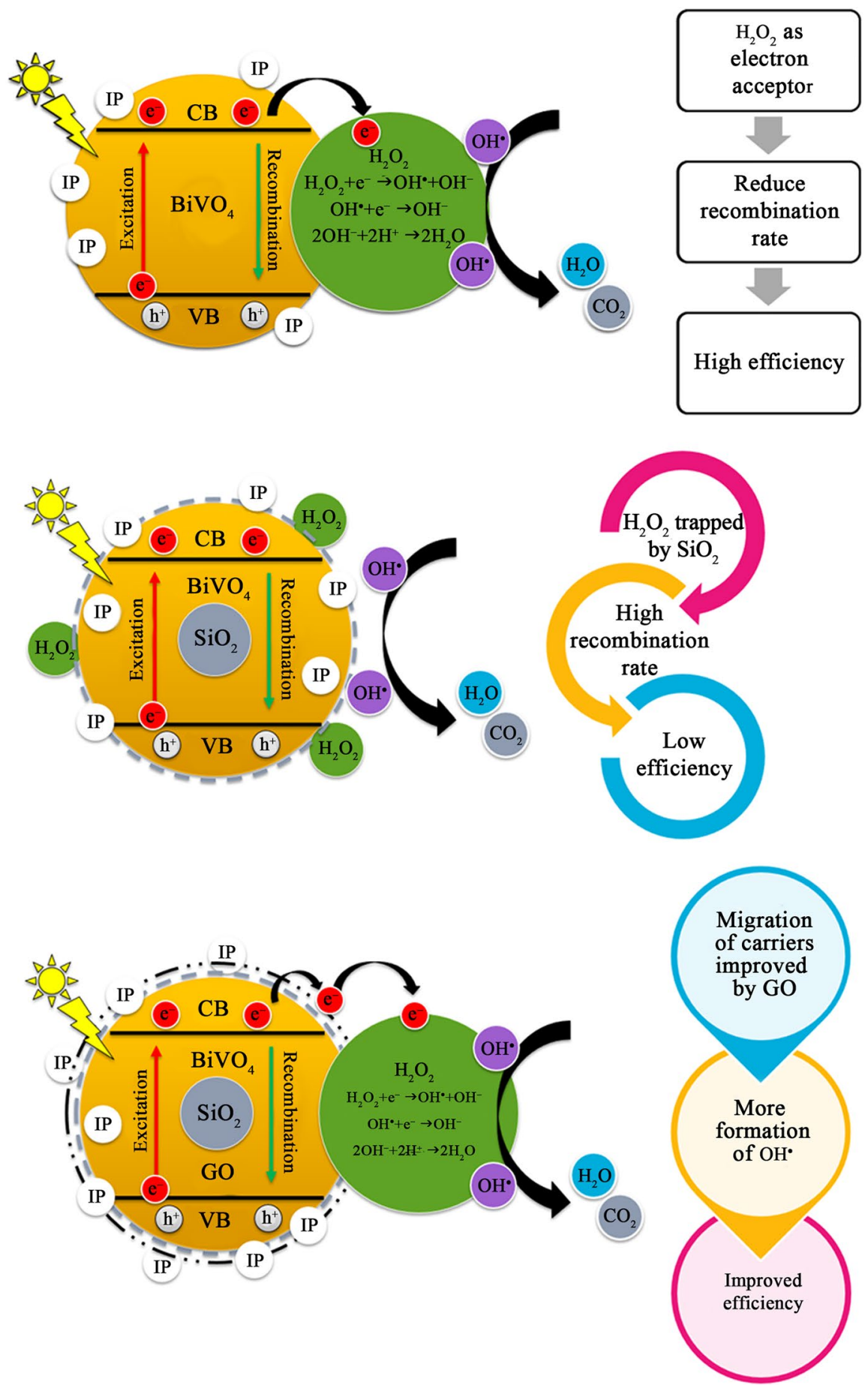

Figure 7. Photodegradation of phenol over $\mathrm{BiVO}_{4}, \mathrm{BiVO}_{4} / \mathrm{SiO}_{2}, \mathrm{BiVO}_{4} / \mathrm{SiO}_{2} / \mathrm{GO}$ with the presence of $\mathrm{H}_{2} \mathrm{O}_{2}$.

nanoparticles showed the highest phenol removal efficiency of $92 \%$ after $6 \mathrm{~h}$ of visible light irradiation. In the meantime, the lowest efficiency was obtained in the $\mathrm{BiVO}_{4} / \mathrm{SiO}_{2}$ core-shell with $48 \%$ of phenol removal.

$$
\begin{gathered}
\mathrm{H}_{2} \mathrm{O}_{2}+\mathrm{e}^{-} \rightarrow \mathrm{OH}^{-}+\mathrm{OH}^{-} \\
\mathrm{OH}^{-}+\mathrm{e}^{-} \rightarrow \mathrm{OH}^{-} \\
2 \mathrm{OH}^{-}+2 \mathrm{H}^{+} \rightarrow 2 \mathrm{H}_{2} \mathrm{O}
\end{gathered}
$$




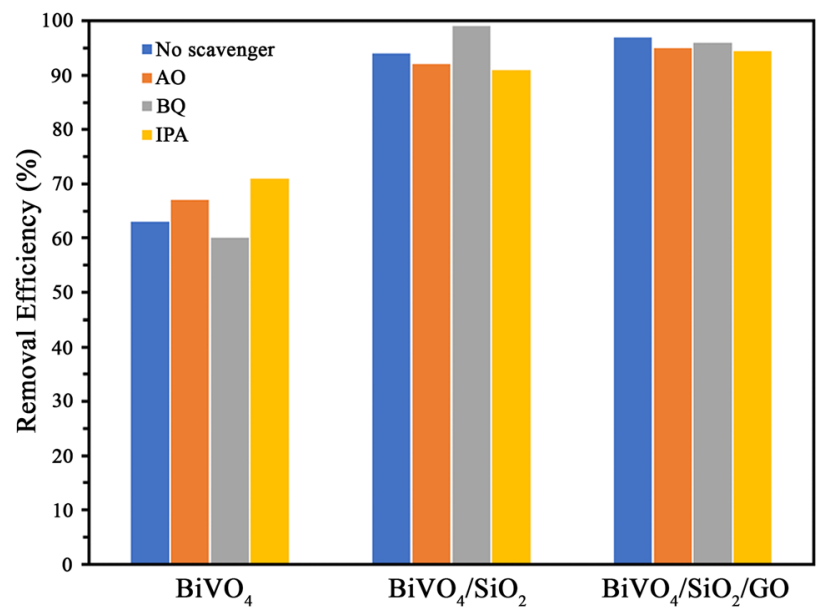

Figure 8. Effect of scavenger on the photodegradation of $\mathrm{MB}$ over $\mathrm{BiVO}_{4}, \mathrm{BiVO}_{4} / \mathrm{SiO}_{2}$ and $\mathrm{BiVO}_{4} / \mathrm{SiO}_{2} / \mathrm{GO}$.

In the case of $\mathrm{BiVO}_{4} / \mathrm{SiO}_{2}$ core-shell, the reactions of $\mathrm{H}_{2} \mathrm{O}_{2}$ could be restricted by $\mathrm{SiO}_{2}$ layer, causing the difficult migration and the fast recombination of charged carriers. However, this inhibition was improved by the addition of GO nanosheets that enhanced the separation of electron-hole pairs. The phenol removal efficiency of $\mathrm{BiVO}_{4} / \mathrm{SiO}_{2} / \mathrm{GO}$ was improved to approximately $70 \%$. This phenomenon is summarized in Fig. 7. Therefore, the best photocatalytic activity was occurred in $\mathrm{BiVO}_{4}$ nanoparticle, followed by $\mathrm{BiVO}_{4} / \mathrm{SiO}_{2} / \mathrm{GO}$ nanocomposite and $\mathrm{BiVO}_{4} / \mathrm{SiO}_{2}$ core-shell. However, the small amount of $\mathrm{H}_{2} \mathrm{O}_{2}$ addition was required to achieve the photocatalytic degradation of phenol. It can be seen that the types of pollutant were affected significantly on the key mechanism of $\mathrm{BiVO}_{4} / \mathrm{SiO}_{2} / \mathrm{GO}$ nanocomposite; the $\mathrm{MB}$ was removed mainly through adsorption due to the improving surface property of nanocomposite, whereas the phenol was removed through photocatalytic degradation due to its poor adsorption ability from phenoxide ions.

Due to the theoritical photocatalytic mechanism, the organic pollutant (i.e., phenol) was degraded by hydroxyl radical of photocatalyst and mineralized to $\mathrm{CO}_{2}$ and water. The organic concentration, represented in term of chemical oxygen demand (COD), was measured in the treated phenol solution to confirm the complete mineraliation and/or the occurance of intermediates. The initial COD concentration was $80 \mathrm{mg} / \mathrm{L}$ and it was decreased to approximately 46,25 and $10 \mathrm{mg} / \mathrm{L}$ for $\mathrm{BiVO}_{4}, \mathrm{BiVO}_{4} / \mathrm{SiO}_{2}$ and $\mathrm{BiVO}_{4} / \mathrm{SiO}_{2} / \mathrm{GO}$ respectively in the $6 \mathrm{~h}$-treated phenol solution. Therefore, the phenol molecule was degraded to small organic compounds, especially using $\mathrm{BiVO}_{4} / \mathrm{SiO}_{2} / \mathrm{GO}$ composite. The possible intermediates during phenol degradation were hydroquinone, benzoquinone, catechol and organic acid ${ }^{26}$. It should be noted that the existing $\mathrm{H}_{2} \mathrm{O}_{2}$ as interfering substrate could have a positive error effected on COD analysis ${ }^{27}$. It is important to be noted that the prove of present hydroxyradical is improtant as presented by several works $2,5,7,12,14,20,23,28$. In addition to the valuation of photocatalytic activity, the active species generated during the $\mathrm{MB}$ photocatalytic degradation were investigated by using scavenger as shown in Fig. 8.

The obtained results indicated that the photocatalytic degradation of $\mathrm{BiVO}_{4}$ was increased by the addition of $\mathrm{AO}$ and IPA. Unfortunately, this result was disagreement with previous studies because the recombination rate of electron-hole pairs of as-prepared $\mathrm{BiVO}_{4}$ was too fast, leading to less formation of hydroxyl radicals. Therefore, scavenger played as intermediate center which can reduce the recombination rate of electron-hole pairs, leading to the increase in photocatalytic degradation. In the meantime, not much change was observed in the photocatalytic process of $\mathrm{BiVO}_{4} / \mathrm{SiO}_{2}$ core-shell and $\mathrm{BiVO}_{4} / \mathrm{SiO}_{2} / \mathrm{GO}$ nanocomposite, because the scavenger can be adsorbed by $\mathrm{SiO}_{2}$ and $\mathrm{GO}$ layers, leading to the slight decrease in photocatalytic degradation. These results suggest that the scavenger test should be only used in the photocatalytic process which has much formation of active species. Figure 9 summarizes the photocatalytic degradation of $\mathrm{MB}$ over $\mathrm{BiVO}_{4}$ nanocomposite, $\mathrm{BiVO}_{4} /$ $\mathrm{SiO}_{2}$ core-shell and $\mathrm{BiVO}_{4} / \mathrm{SiO}_{2} / \mathrm{GO}$ nanocomposite in the presence of scavenger.

\section{Conclusions}

In the present work, the $\mathrm{BiVO}_{4} / \mathrm{SiO}_{2} / \mathrm{GO}$ nanocomposite was synthesized successfully by one-step solvothermal method. Nanocomposite was formed by the uniform adhesion of $\mathrm{SiO}_{2}$ and $\mathrm{BiVO}_{4}$ on $\mathrm{GO}$ nanosheets. Due to the low content of $\mathrm{SiO}_{2}$ and $\mathrm{GO}$, the $\mathrm{BiVO}_{4} / \mathrm{SiO}_{2} / \mathrm{GO}$ nanocomposite exhibited the same XRD peaks of monoclinic $\mathrm{BiVO}_{4}$ without others contamination phase. The $\mathrm{BiVO}_{4} / \mathrm{SiO}_{2} / \mathrm{GO}$ showed the highest surface area of $43.93 \mathrm{~m}^{2} / \mathrm{g}$, conversely the $\mathrm{BiVO}_{4}$ had only $11.13 \mathrm{~m}^{2} / \mathrm{g}$. The $\mathrm{BiVO}_{4} / \mathrm{SiO}_{2} / \mathrm{GO}$ nanocomposite showed the higher adsorption ability rather than the photocatalytic degradation for $\mathrm{MB}$ removal. The enhancement of photocatalytic degradation was observed for phenol removal under $\mathrm{H}_{2} \mathrm{O}_{2}$ assistance. The $\mathrm{BiVO}_{4}$ nanoparticle still obtained the best photocatalytic ability than $\mathrm{BiVO}_{4} / \mathrm{SiO}_{2}$ core-shell and $\mathrm{BiVO}_{4} / \mathrm{SiO}_{2} / \mathrm{GO}$ nanocomposite. Although both $\mathrm{SiO}_{2}$ and $\mathrm{GO}$ were great property materials which able to improve the photocatalytic ability of $\mathrm{BiVO}_{4}$, the improper combination ratio caused the nanocomposite containing high adsorption ability and low photocatalytic degradation, as presented in this work. This is very important to be noted that the optimal combination ratio is essential to archive the greatest nanocomposite for photocatalytic application. 

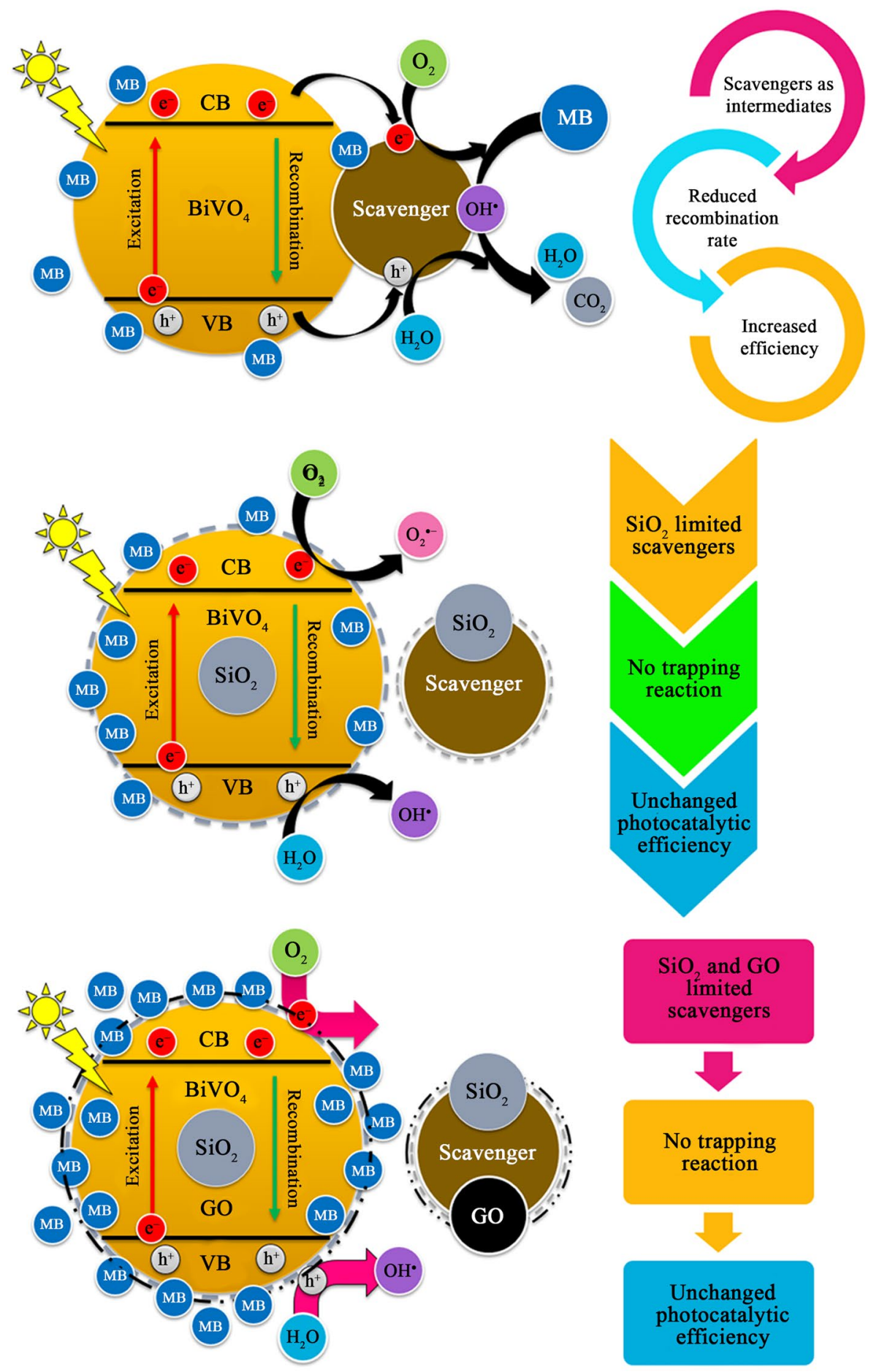

Figure 9. Photodegradation of $\mathrm{MB}$ over $\mathrm{BiVO}_{4}, \mathrm{BiVO}_{4} / \mathrm{SiO}_{2}, \mathrm{BiVO}_{4} / \mathrm{SiO}_{2} / \mathrm{GO}$ with the addition of scavenger.

Received: 18 December 2020; Accepted: 15 February 2021

Published online: 25 February 2021

\section{References}

1. Liu, Y., Jin, W., Zhao, Y., Zhang, G. \& Zhang, W. Enhanced catalytic degradation of methylene blue by $a-\mathrm{Fe}_{2} \mathrm{O}_{3} /$ graphene oxide via heterogeneous photo-Fenton reactions. Appl. Catal. B 206, 642-652. https://doi.org/10.1016/j.apcatb.2017.01.075 (2017).

2. Zhang, $\mathrm{H}$. et al. Construction of a novel $\mathrm{BON}-\mathrm{Br}-\mathrm{AgBr}$ heterojunction photocatalysts as a direct Z-scheme system for efficient visible photocatalytic activity. Appl. Surf. Sci. 497, 143820. https://doi.org/10.1016/j.apsusc.2019.143820 (2019). 
3. Al-Mamun, M. R., Kader, S., Islam, M. S. \& Khan, M. Z. H. Photocatalytic activity improvement and application of UV-TiO pho- $^{-}$ tocatalysis in textile wastewater treatment: A review. J. Environ. Chem. Eng. 7, 103248. https://doi.org/10.1016/j.jece.2019.10324 8 (2019).

4. Ceretta, M. B., Vieira, Y., Wolski, E. A., Foletto, E. L. \& Silvestri, S. Biological degradation coupled to photocatalysis by ZnO/ polypyrrole composite for the treatment of real textile wastewater. J. Water Process Eng. 35, 101230. https://doi.org/10.1016/j. jwpe.2020.101230 (2020)

5. Yang, R., Zhong, S., Zhang, L. \& Liu, B. $\mathrm{PW}_{12} / \mathrm{CN} @ \mathrm{Bi}_{2} \mathrm{WO}_{6}$ composite photocatalyst prepared based on organic-inorganic hybrid system for removing pollutants in water. Sep. Purif. Technol. 235, 116270. https://doi.org/10.1016/j.seppur.2019.116270 (2020).

6. Trinh, D. T. T., Channei, D., Chansaenpak, K., Khanitchaidecha, W. \& Nakaruk, A. Photocatalytic degradation of organic dye over bismuth vanadate-silicon dioxide-graphene oxide nanocomposite under visible light irradiation. J. Aust. Ceram. Soc. 56, 1237-1241. https://doi.org/10.1007/s41779-020-00470-4 (2020).

7. Wang, Y. et al. Fabrication of $\mathrm{BiVO}_{4} / \mathrm{BiPO}_{4} / \mathrm{GO}$ composite photocatalytic material for the visible light-driven degradation. J. Clean. Prod. 247, 119108. https://doi.org/10.1016/j.jclepro.2019.119108 (2020).

8. Zhu, X.-D., Wang, Y.-J., Sun, R.-J. \& Zhou, D.-M. Photocatalytic degradation of tetracycline in aqueous solution by nanosized $\mathrm{TiO}_{2}$. Chemosphere 92, 925-932. https://doi.org/10.1016/j.chemosphere.2013.02.066 (2013).

9. Ahmed, T., Zhang, H.-L., Gao, Y.-Y., Xu, H.-B. \& Zhang, Y. Surfactant-free synthesis of $\mathrm{m}_{-} \mathrm{BiVO}_{4}$ nanoribbons and enhanced visible-light photocatalytic properties. Mater. Res. Bull. 99, 298-305. https://doi.org/10.1016/j.materresbull.2017.11.029 (2018).

10. Zhu, Z., Han, Q., Yu, D., Sun, J. \& Liu, B. A novel p-n heterojunction of $\mathrm{BiVO}_{4} / \mathrm{TiO}_{2} / \mathrm{GO}$ composite for enhanced visible-lightdriven photocatalytic activity. Mater. Lett. 209, 379-383. https://doi.org/10.1016/j.matlet.2017.08.045 (2017).

11. Lin, L. et al. Preparation of $\mathrm{BiVO}_{4} / \mathrm{Bi}_{2} \mathrm{WO}_{6} /$ multi-walled carbon nanotube nanocomposites for enchaning photocatalytic performance. Mater. Lett. 185, 507-510. https://doi.org/10.1016/j.matlet.2016.09.063 (2016)

12. Yang, R. et al. Facile synthesis and characterization of interface charge transfer heterojunction of $\mathrm{Bi}_{2} \mathrm{MoO}_{6}$ modified by $\mathrm{Ag} /$ AgCl photosensitive material with enhanced photocatalytic activity. Mater. Lett. 252, 272-276. https://doi.org/10.1016/j.matle t.2019.06.006 (2019).

13. Ketwong, P., Takashima, M., Nitta, A., Pookmanee, P. \& Ohtani, B. Hydrothermal synthesis and photocatalytic activities of stabilized bismuth vanadate/bismuth tungstate composites. J. Environ. Chem. Eng. 6, 2048-2054. https://doi.org/10.1016/j.jece.2018.01.062 (2018).

14. Wang, Y. et al. Synthesizing $\mathrm{Co}_{3} \mathrm{O}_{4}-\mathrm{BiVO}_{4} / \mathrm{g}-\mathrm{C}_{3} \mathrm{~N}_{4}$ heterojunction composites for superior photocatalytic redox activity. Sep. Purif. Technol. 239, 116562. https://doi.org/10.1016/j.seppur.2020.116562 (2020).

15. Li, R., Han, H., Zhang, F., Wang, D. \& Li, C. Highly efficient photocatalysts constructed by rational assembly of dual-cocatalysts separately on different facets of $\mathrm{BiVO}_{4}$. Energy Environ. Sci. 7, 1369-1376. https://doi.org/10.1039/C3EE43304H (2014).

16. Trinh, D. T. T., Khanitchaidecha, W., Channei, D. \& Nakaruk, A. Synthesis, characterization and environmental applications of bismuth vanadate. Res. Chem. Intermed. 45, 5217-5259. https://doi.org/10.1007/s11164-019-03912-2 (2019).

17. Channei, D., Nakaruk, A., Khanitchaidecha, W., Jannoey, P. \& Phanichphant, S. Adsorption and photocatalytic processes of mesoporous $\mathrm{SiO}_{2}$-coated monoclinic $\mathrm{BiVO}_{4}$. Front. Chem. 6, 415-415. https://doi.org/10.3389/fchem.2018.00415 (2018).

18. Liu, B., Wang, Z., Zhou, S. \& He, J. Synthesis and characterization of a novel $\mathrm{BiVO}_{4} / \mathrm{SiO}_{2}$ nanocomposites. Mater. Lett. 160, $218-221$. https://doi.org/10.1016/j.matlet.2015.07.104 (2015).

19. Zhou, D., Zhu, Z. \& Liu, B. Solvothermal synthesis and characterization of a novel reduced graphene oxide $\left(\mathrm{RGO} / \mathrm{BiVO}_{4} / \mathrm{SiO}_{2}\right.$ nanocomposites. Mater. Lett. 185, 32-35. https://doi.org/10.1016/j.matlet.2016.08.098 (2016).

20. Liu, B. et al. Construction of fiber-based $\mathrm{BiVO}_{4} / \mathrm{SiO}_{2} /$ reduced graphene oxide (RGO) with efficient visible light photocatalytic activity. Cellulose 25, 1089-1101. https://doi.org/10.1007/s10570-017-1628-8 (2018)

21. Tahir, M. B., Iqbal, T., Kiran, H. \& Hasan, A. Insighting role of reduced graphene oxide in $\mathrm{BiVO}_{4}$ nanoparticles for improved photocatalytic hydrogen evolution and dyes degradation. Int. J. Energy Res. 43, 2410-2417. https://doi.org/10.1002/er.4443 (2019).

22 Trinh, D. T. T., Channei, D., Khanitchaidecha, W. \& Nakaruk, A. Photocatalytic degradation of organic contaminants by BiVO ${ }_{4}$ graphene oxide nanocomposite. Walailak J. Sci. Technol. 15, 787-792. https://doi.org/10.48048/wjst.2018.5969 (2018).

23. Yang, R. et al. One-step preparation (3D/2D/2D) $\mathrm{BiVO}_{4} / \mathrm{FeVO}_{4} @ \mathrm{rGO}$ heterojunction composite photocatalyst for the removal of tetracycline and hexavalent chromium ions in water. Chem. Eng. J. 390, 124522. https://doi.org/10.1016/j.cej.2020.124522 (2020).

24. Rouquerol, J., Llewellyn, P. \& Rouquerol, F. In Studies in Surface Science and Catalysis Vol. 160 (eds Llewellyn, P.L. et al.) 49-56 (Elsevier, 2007).

25. Sing, K. S. W. \& Williams, R. T. Physisorption hysteresis loops and the characterization of nanoporous materials. Adsorpt. Sci. Technol. 22, 773-782. https://doi.org/10.1260/0263617053499032 (2004).

26. Meng, X., Li, Z. \& Zhang, Z. Palladium nanoparticles and $\mathrm{rGO}$ co-modified $\mathrm{BiVO}_{4}$ with greatly improved visible light-induced photocatalytic activity. Chemosphere 198, 1-12. https://doi.org/10.1016/j.chemosphere.2018.01.070 (2018).

27. Talinli, I. \& Anderson, G. K. Interference of hydrogen peroxide on the standard cod test. Water Res. 26, 107-110. https://doi. org/10.1016/0043-1354(92)90118-N (1992).

28. Chen, H.-H., Jiang, Z.-H., Li, X.-D. \& Lei, X.-F. Effect of cerium nitrate concentration on morphologies, structure and photocatalytic activities of $\mathrm{CeO}_{2}$ nanoparticles synthesized by microwave interface method. Mater. Lett. 257, 126666. https://doi.org/10.1016/j. matlet.2019.126666 (2019).

\section{Acknowledgements}

The authors would like to acknowledge Faculty of Engineering, Naresuan University, Thailand for partial funding support. Dr. Dang Trung Tri Trinh wishes to thank Naresuan University for international Ph.D. Scholarship. The authors also would like to thank Kairop and Milint Nakaruk for the donation of their living allowance to support article processing charges.

\section{Author contributions}

D.T.T.T. has performed experiment and data analysis. D.C. has did data analysis and wrote manuscript. A.N. did experimental design, data analysis and wrote manuscript. W.K. did experimental design, data analysis, and wrote main manuscript.

\section{Competing interests}

The authors declare no competing interests.

\section{Additional information}

Supplementary Information The online version contains supplementary material available at https://doi. org/10.1038/s41598-021-84323-5.

Correspondence and requests for materials should be addressed to W.K. 
Reprints and permissions information is available at www.nature.com/reprints.

Publisher's note Springer Nature remains neutral with regard to jurisdictional claims in published maps and institutional affiliations.

(c) (i) Open Access This article is licensed under a Creative Commons Attribution 4.0 International License, which permits use, sharing, adaptation, distribution and reproduction in any medium or format, as long as you give appropriate credit to the original author(s) and the source, provide a link to the Creative Commons licence, and indicate if changes were made. The images or other third party material in this article are included in the article's Creative Commons licence, unless indicated otherwise in a credit line to the material. If material is not included in the article's Creative Commons licence and your intended use is not permitted by statutory regulation or exceeds the permitted use, you will need to obtain permission directly from the copyright holder. To view a copy of this licence, visit http://creativecommons.org/licenses/by/4.0/.

(C) The Author(s) 2021 